Japanese Journal of Physiology, 30, 93-104, 1980

\title{
Study on Tubular Transient Current and Mechanical Activation in Skeletal Muscle of Frog
}

\author{
Toshiharu Ова and Ken Нотта \\ Department of Physiology, Nagoya City University \\ Medical School, Nagoya, 467 Japan
}

\begin{abstract}
The relation between membrane current and mechanical activity during excitation of frog muscle fibers was studied using twomicroelectrode voltage clamp technique. The current flow upon excitation of membrane consisted of transient initial inward and subsequent outward currents which were carried by $\mathrm{Na}^{+}$influx and $\mathrm{K}^{+}$efflux, respectively. Blocking of the outward $\mathrm{K}^{+}$current by 3,4-diaminopyridine resulted in appearance of a late inward current associated with marked potentiation of twitch tension. Detubulation of the fiber by treatment with hypertonic glycerol suppressed the outward $\mathrm{K}^{+}$current as well as the late inward current and abolished the contractile force. Dantrolene also gave similar effects on membrane currents and reduced twitch tension markedly. These results suggest that the late inward current through the $\mathrm{T}$-system and not the outward $\mathrm{K}^{+}$current may be the first step to lead the muscle cell to mechanical activation.
\end{abstract}

In the skeletal muscle, it is certain that the transverse tubular membrane (T-system) plays an essential role in activation of the contractile system upon excitation of cell membrane (E-C coupling). Several works have appeared to show that the $\mathrm{Na}^{+}$-dependent regenerative process on the $\mathrm{T}$-system is involved in the mechanical activation of muscle fiber (Costantin, 1970; CAPUTO and Dipolo, 1973; BeZanilla et al., 1972; Bastian and NaKaJima, 1974). Recently, a $\mathrm{Na}^{+}$-dependent, regenerative inward current through the $\mathrm{T}$-system was detected using the voltage clamp technique (CAILlE et al., 1975; MANDRINO, 1977). The appearance of a $\mathrm{Ca}^{2+}$-dependent current flow during excitation was also demonstrated by Stanfield (1977), TAKeda (1977) and SAuchez and STEFANi (1978). However, how these ionic currents contribute to the generation of twitch tension remains to be answered. In fact, there is no report which deals with possible relations between tubular current and mechanical activation except for a brief paper of CAILlE et al. (1975). The voltage clamp technique by ADRIAN et al. (1970), which has been used by most of the workers on skeletal muscle, is not

Received for publication July 9, 1979

大羽利治, 堀田 健 
suitable for the simultaneous observation of membrane current and mechanical activity of muscle because the fiber in which three electrodes are inserted may be seriously damaged by the contraction of the muscle.

In the present work, an attempt was made to obtain direct relationships between membrane current and generation of twitch tension by simultaneous recordings. For this purpose, a voltage clamp was made by a conventional twomicroelectrode technique. The electrodes were inserted into a fiber near its fixed end to minimize the possible injury to the fiber during its mechanical activation. Several pharmacological agents which have been known as selective membrane current blockers were used in this study. Besides TTX and TEA, well-known $\mathrm{Na}^{+}$and $\mathrm{K}^{+}$channel blockers, respectively, 3,4-diaminopyridine was used for blocking $\mathrm{K}^{+}$channel. This agent exhibited a much more powerful inhibitory effect on $\mathrm{K}^{+}$channel than TEA and important information on late inward current was obtained by using this agent. Preliminary result of this experiment has already been reported (HotTA et al., 1978).

\section{MATERIALS AND METHODS}

Sample and bathing medium. Fiber bundles containing approximately 10 fibers ( $80 \mu \mathrm{m}$ diameter, $3 \mathrm{~cm}$ long) were obtained from semitendinosus muscle of bullfrog. The sample connected to the tension transducer (Toyota SP-5-120) was incubated in a temperature-controlled bath containing Ringer solution (in $\mathrm{mM}$, $\mathrm{NaCl}, 105 ; \mathrm{KCl}, 2.5 ;$ glucose, $10 ; \mathrm{CaCl}_{2}, 1.8$ and tris-maleate, $10 ; \mathrm{pH} \mathrm{7.0)}$ as shown in Fig. 1. All measurements were performed at $4^{\circ} \mathrm{C}$.

Electrodes and voltage clamp. Two electrodes filled with $3 \mathrm{M} \mathrm{KCl}$ and having

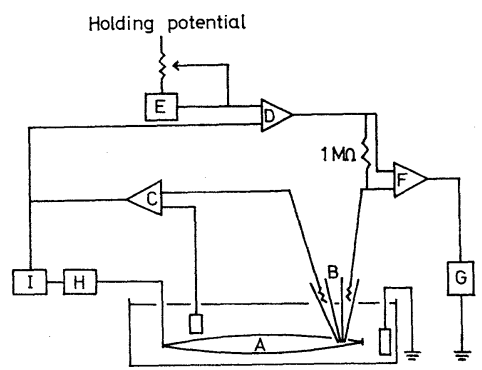

Fig. 1. A block diagram of the system for voltage clamping of the muscle fiber and measuring membrane currents. A, muscle fiber; B, electrodes; C, differential amplifier (MEZ 7101, Nihon Kohden); D, clamping amplifier (CEZ 1101, Nihon Kohden). The feedback loop contains a $5 \mathrm{k} \Omega$ variable resistor for adjustment of gain from $10^{2}$ to $10^{4}$ with maximum output voltage of $\pm 12 \mathrm{~V}$. Current flow through the $1 \mathrm{M} \Omega$ resistor was amplified by current amplifier (F) and recorded on ATAC $250(\mathrm{G})$. H, semiconductor strain gauge (Sp-5-120, Toyota Central Lab.); E, stimulator; I, polyrecorder (PMP 3004, Nihon Kohden). 
the impedance of about 6 and $10 \mathrm{M} \Omega$ were used for passing current and measuring membrane potential, respectively. The distance of two electrodes was $100 \mu \mathrm{m}$. A block diagram of the system for voltage clamp and simultaneous recordings of membrane current and tension generation is shown in Fig. 1. Upon the feedback signal from the voltage electrodes, the current necessary to depolarize the membrane potential to the desired value was supplied through the clamp amplifier (CEZ-1100, Nihon Kohden). The total current was measured as voltage drop through a $1 \mathrm{M} \Omega$ resistor and led to a memory scope (ATAC 250, Nihon Kohden), and its output was recorded on a conventional recorder (VP-6538, National). The holding potential was fixed at the resting potential. Current, tension development and membrane potential change were simultaneously recorded on a fourchannel polyrecorder (PMP-3004, Nihon Kohden).

Specific channel blockers. As the selective inhibitors of ionic permeabilities for $\mathrm{Na}^{+}$and $\mathrm{K}^{+}$, tetrodotoxin (TTX, $3 \times$ crystallized, Sankyo), tetraethylammonium chloride (TEA, Tokyo Kasei) and 3,4-diaminopyridine (DAP, Tokyo Kasei) were used. According to KIRSHE and NARAHASHI (1978), DAP was a much more potent and specific $\mathrm{K}^{+}$channel blocker than TEA in squid giant axon.

Glycerol treatment of the fibers were achieved according to the procedures described by EISENBERG et al. (1971). Dantrolene-Na which has been known as a muscle relaxing agent (Ellis and BRYANT, 1972; ОвA and HotTA, 1978) was obtained from the Yamanouchi Pharmaceutical Co. The other reagents used were of the best grade commercially available.

\section{RESULTS}

Typical recordings of twitch tension (top) and the total current (middle) are shown in Fig. 2a with the depolarizing pulse from the holding (resting) potential (bottom). Application of depolarizing pulse around the threshold $(27 \mathrm{mV})$ having long duration induced the transient inward and subsequent outward currents and twitch tension upon excitation of membrane. The time lag from the onset of depolarization to the excitation of membrane varied depending on the degree of depolarization: larger depolarization resulted in earlier occurrence of excitation and occasionally, repetitive excitation associated with summation of tension were observed, as shown in Fig. 2 b.

Upon onset of depolarization, an upward signal, which lasted 15-20 msec, appeared. Application of a hyperpolarizing pulse of the same size induced an identical signal in opposite direction. Thus, this signal was originated from the capacitance of the system as pointed out by ILDEFONSE and ROUGIER (1972). We could not eliminate this artificial current effectively, however, it gave virtually no influence on the membrane current because the capacitive current diminished before initiation of the ionic current (Fig. 2c).

Amplitude of the inward current increased drastically when the fiber was

Vol. 30, No. 1,1980 


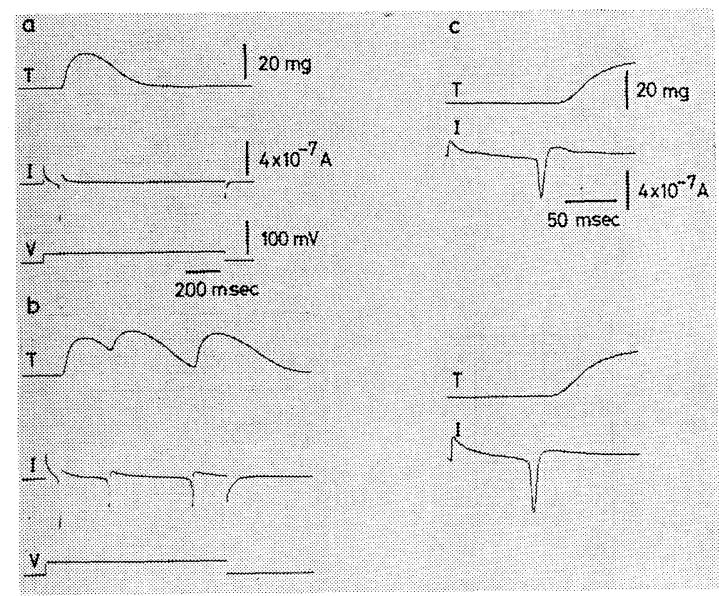

Fig. 2. Recordings of twitch tension $(T)$ and current flow $(I)$ across the membrane on the response to the depolarizing pulse $(V)$ with a duration of $1 \mathrm{sec}$ from the holding potential $(-87 \mathrm{mV})$. (a) A response of muscle fiber obtained by the threshold depolarizing pulse $(27 \mathrm{mV})$. Note the transient inward (downward deflection) and subsequent outward (upward) currents. (b) A response to the suprathreshold depolarizing pulse $(40 \mathrm{mV})$. Three different current flows with summation of twitch tension can be observed. (c) The expansion of the time scale of figure (a) and (b). The time required for the onset of tension generation from peak of inward current was calculated from these recordings.

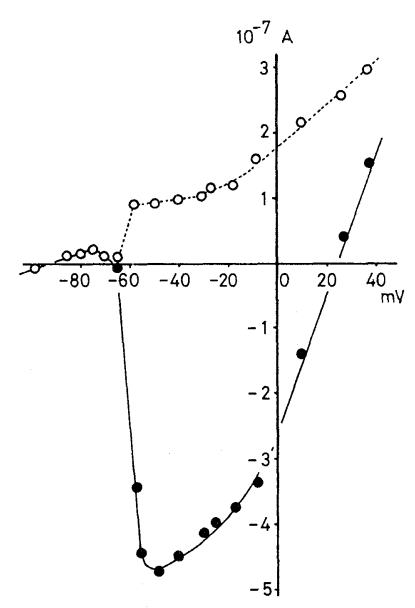

Fig. 3. Relation between membrane current and voltage during depolarizing step in normal Ringer solution ( $I-V$ curve). $\bullet$, inward current; $\bigcirc$, outward current. Holding potential, $-89 \mathrm{mV}$.

depolarized by $25 \mathrm{mV}$ from the holding level and reached to a maximum at about $40 \mathrm{mV}$ depolarization, followed by the gradual decrease as shown in Fig. 3 . The inward current was not observed when the depolarization exceeded $+20 \mathrm{mV}$ 
Table 1. The effect of dantrolene $(40 \mu \mathrm{M})$ on tension and the time $(T)$ required for the onset of force generation from the peak of the initial inward current.

\begin{tabular}{lcccc}
\hline & $\begin{array}{c}\text { No. of fibers } \\
\text { treated }\end{array}$ & $\begin{array}{c}\text { Resting potential } \\
(\mathrm{mV})\end{array}$ & $\begin{array}{c}\text { Tension } \\
(\mathrm{mg})\end{array}$ & $\begin{array}{c}T \\
(\mathrm{msec})\end{array}$ \\
\hline $\begin{array}{l}\text { Normal } \\
\text { Ringer }\end{array}$ & 20 & $-83.0 \pm 1.3$ & $33.7 \pm 4.3$ & $25.5 \pm 1.1$ \\
\hline $\begin{array}{l}\text { DAN } \\
\text { Ringer }\end{array}$ & 12 & $-83.9 \pm 2.6$ & $5.2 \pm 1.7^{* *}$ & $31.7 \pm 1.2^{*}$ \\
\hline
\end{tabular}

Measurements in DAN Ringer were performed at least 7 min after the drug application. Values are mean \pm S.E.M. Significant difference from the controls: $* P<0.05$, ** $P<0.01$.

(near $\mathrm{Na}^{+}$equilibrium potential). The outward current began to appear at the point where the inward current was generated, however, its intensity remained approximately constant up to $70 \mathrm{mV}$ depolarization from the resting level (Fig. 3). Figure $2 c$ which was obtained from Fig. $2 a$ and $b$ by the expansion of time scale, shows the time required for the onset of tension generation from the peak of the inward current. The tension development was observed $25.5 \pm 1.1 \mathrm{msec}$ after the peak point of the inward current (Table 1).

\section{Effect of TTX}

TTX at a dose of $10^{-7} \mathrm{~g} /$ liter abolished the inward current within a very
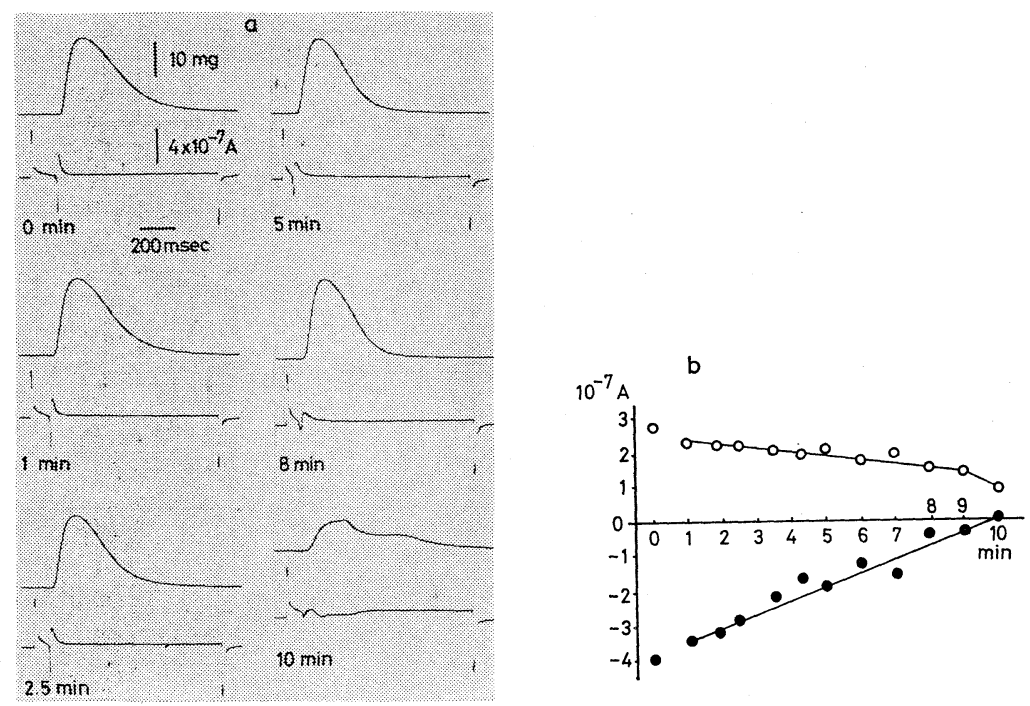

Fig. 4. Influence of TTX $\left(7 \times 10^{-8} \mathrm{~g} /\right.$ liter $)$ on the initial inward and subsequent outward currents. The threshold depolarizing pulse was applied to the fiber. (a) Recordings of tension (upper trace) and current (lower trace). Time indicates after incubation in TTX Ringer solution. Zero min represents time immediately before exposure to TTX Ringer. (b) Time courses of change of inward ( $)$ and outward $(0)$ currents. 
short time. Thus, this current is identified as the one carried by $\mathrm{Na}^{+}$upon excitation of cell membrane. At low concentrations of TTX $\left(4-7 \times 10^{-8} \mathrm{~g} /\right.$ liter $)$, reduction of the inward current occurred rather slowly, so that the time course of its inhibition could be followed. Figure $4 \mathrm{a}$ shows a series of simultaneous recordings of membrane current under the voltage clamp and twitch tension induced by the threshold depolarizing pulse in the presence of $7 \times 10^{-8} \mathrm{~g} /$ liter TTX. At 8 min after incubation in TTX Ringer solution, only a small portion of the initial inward current remained, however, considerable outward current was still observable. This indicates that the outward current is not carried by $\mathrm{Na}^{+}$although it is dependent on the preceding $\mathrm{Na}^{+}$current. Nevertheless, the fiber developed considerable twitch tension upon excitation until inward and outward currents were completely diminished (more than $10 \mathrm{~min}$ incubation in TTX Ringer solution). Therefore, it seems that the initial $\mathrm{Na}^{+}$current flow is not directly related to the tension generation of the fiber (Ca release mechanism for E-C coupling).

\section{Effects of TEA and DAP}

Twenty mM TEA in the Ringer solution blocked the transient outward current within one min without affecting the preceding inward current (Fig. 5). This suggests that the outward current is carried by outflow of $\mathrm{K}^{+}$. The tension development was augmented by more than $20 \%$ in the presence of TEA.

When the fiber bundles were treated with DAP at a dose of $100 \mu \mathrm{M}$, the outward current was reduced and a small inward current (late inward current) appeared immediately after the peak of the outward current (Fig. 6). This current had a slower time course than that of the initial one and the amplitude seemed to depend on the diameter of the fiber used, i.e., the late inward current could not be

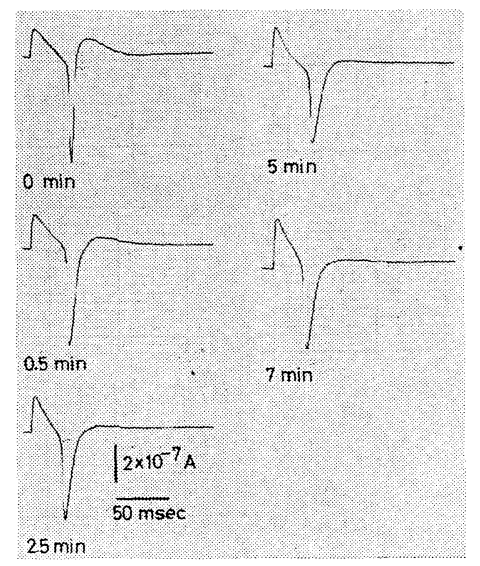

Fig. 5. Disappearance of the outward current by TEA $(20 \mathrm{~mm})$ : Recording of the current after application of TEA at $0.5,2.5,5$ and $7 \mathrm{~min}$. Zero min represents before the addition of TEA. Within $5 \mathrm{~min}$, the outward current diminished completely and duration of inward current was prolonged. Holding potential, $-84 \mathrm{mV}$. 


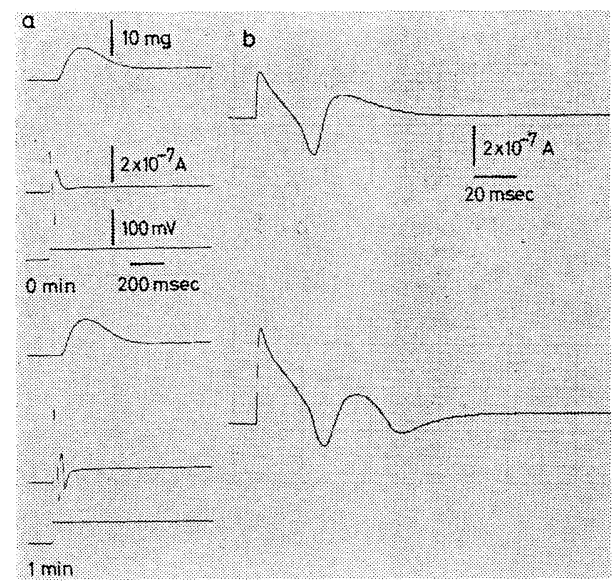

Fig. 6. Appearance of late inward current by 3,4-diaminopyridine. (a) Recordings of tension (upper trace), current (middle trace) upon depolarizing pulse (lower trace) before (top figures) and one min after (bottom figures) DAP treatment. A late inward current appeared immediately after the peak of outward current. (b) Expansion of time scale of current. Top, in normal Ringer; bottom, in DAP Ringer one min after incubation. The time lag between the peaks of initial and late inward currents was $37 \mathrm{msec}$ in this case. The twitch tension was augmented about $10 \%$.

observed in fibers with small diameter less than $50 \mu \mathrm{m}$. In some cases of large fibers with the diameter more than $90 \mu \mathrm{m}$, the small late inward current could be distinguished from outward current $\left(\mathrm{K}^{+}\right)$without blocking $\mathrm{K}^{+}$channel. The time lag between the peaks of initial and late inward currents was approximately $30 \mathrm{msec}$. Consequently, the late inward current normally seemed to be hidden behind the outward current, but it became observable when the outward current was blocked by DAP. The twitch tension was greatly enhanced by more than $50 \%$ with $100 \mu \mathrm{M}$ DAP in the Ringer solution.

\section{Effect of detubulation}

Ability to generate tension of the detubulated fiber was completely abolished by the treatment with $400 \mathrm{~mm}$ hypertonic glycerol Ringer for 20 min upon returning to normal Ringer. There was no change in intensity of the initial inward current of the fiber upon depolarization, except for prolongation of its duration, however, the amplitude and duration of the outward current were reduced and prolonged, respectively. By treatment of the sample in hypertonic glycerol for $1 \mathrm{hr}$, the prolongation of the duration in both inward and outward currents became clearly evident, as shown in Fig. 7. The prolonged duration of the initial inward current is mainly attributed to the reduction of following outward current which overlaps the late part of initial inward current. These results strongly suggest that the outward flow of $\mathrm{K}^{+}$through the $\mathrm{T}$-tubular membrane upon depolarization contributes to the most part of this transient outward current. 


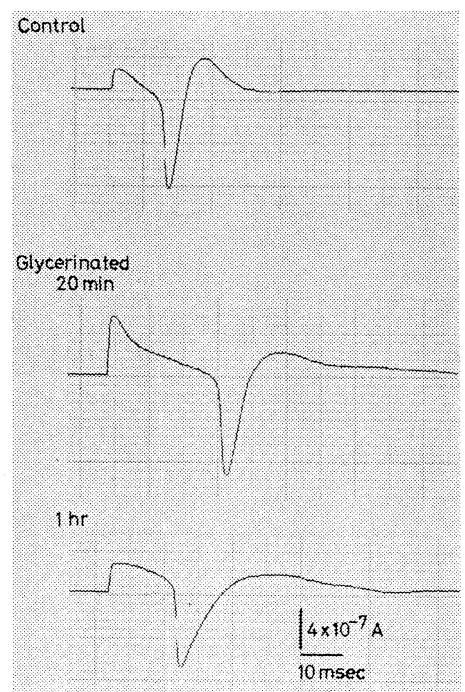

Fig. 7. Current in the muscle fiber treated with $400 \mathrm{~mm}$ hypertonic glycerol. Top, control; middle, treated with glycerol for $20 \mathrm{~min}$; bottom, treated with glycerol for $1 \mathrm{hr}$. Glycerol treated fibers did not develop tension either in $20 \mathrm{~min}$ or $1 \mathrm{hr}$ treatment. Note that the durations of both inward and outward currents were prolonged by the glycerol treatment.

\section{Effect of dantrolene}

The presence of dantrolene in a low concentration $(4 \mu \mathrm{M})$ in Ringer solution gave no appreciable effect on membrane current generated by threshold depolarizing pulse, although the tension was reduced to less than $1 / 3$ of that of control

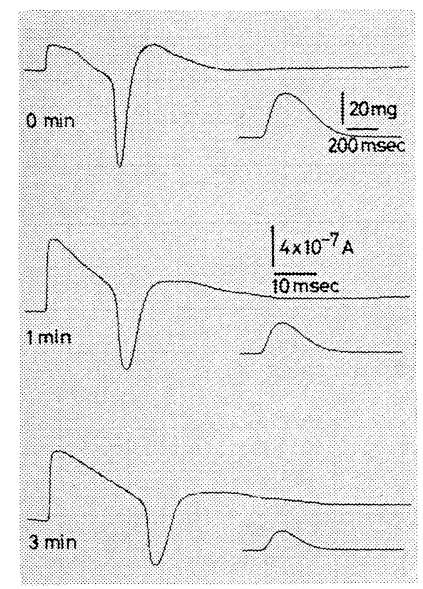

Fig. 8. Effect of dantrolene-Na $(40 \mu \mathrm{M})$ on current and tension. Top, control; middle, $1 \mathrm{~min}$ after application of DAN; bottom, $3 \mathrm{~min}$ after application of DAN. The tension developed was reduced to $40 \%$ of control. Holding potential, $-87 \mathrm{mV}$. 
within $10 \mathrm{~min}$. High concentration of dantrolene $(40 \mu \mathrm{M})$ reduced the tension of the fibers much faster than that in the lower concentration and the outward current was reduced and prolonged as in the case of detubulated muscle fibers, however, the late inward current was not observed (Fig. 8). Dantrolene also delayed the initiation of tension upon excitation of membrane as represented by the time required for the onset of force generation from the peak of the initial inward current (Table 1).

\section{DISCUSSION}

Since the first report by ADRIAN et al. (1970) to use three microelectrodes for the voltage clamp of skeletal muscle fibers, several works have appeared on the electrical phenomenon of skeletal muscle membrane employing this technique. Most of those experiments were performed under conditions in which the mechanical activity of muscle was suppressed in hypertonic solution to avoid possible implications due to movement. With three electrodes, the fiber also would be seriously injured by the contraction. Consequently, electrical events that occurred during excitation could not be correlated with contractile activity by those experiments. MANDRINo (1977) detected the $\mathrm{Na}^{+}$-dependent, late inward current which flows through the T-system. This $\mathrm{Na}^{+}$current (tubular current) would be the immediate trigger for the mechanical activation (Ca release from SR). However, relation between tubular current and the activation of contractile system has not been observed.

Our purpose in this experiment is to find out the relation between electrical phenomenon and initiation of contraction ( $\mathrm{Ca}$ release) during excitation-contraction coupling. The advantage of using two electrodes for voltage clamp was that it was possible to make simultaneous recordings of mechanical activity and membrane current repeatedly with minimum injury to the fiber. Actually, the two electrode voltage clamp method has been successfully applied by TAKEDA (1977) and STANFIELD (1977) to detect the slow inward current (tubular current) from frog skeletal muscle fiber. The mechanical activity may give some interference on the electrical current measurements, however, it could not be serious because onset of contractile force begun to appear 20 to $30 \mathrm{msec}$ after the excitation of membrane (Table 1) where most of the electrical events concerned here had been completed.

The initial inward current observed here is the one which has been commonly recognized in nerve and skeletal muscle cells as a regenerative $\mathrm{Na}^{+}$influx through the cell membrane upon excitation, because this current was inhibited by TTX, the $\mathrm{Na}^{+}$channel blocker. However, the subsequent transient outward current differs in nature from that recognized as a slow $\mathrm{K}^{+}$current (ADRIAN et al., 1970) in the following respects: (1) this current is dependent on the initial $\mathrm{Na}^{+}$current and (2) inactivation occurs quite rapidly (time constant, order of $10 \mathrm{msec}$, Fig. 6) at $4^{\circ} \mathrm{C}$. The initial inward current-dependent, transient $\mathrm{K}^{+}$current has been ob- 
served by Mounier and Vassort (1975) and HenceK and ZACHAR (1977) in crab and crayfish muscles, respectively. It has been known that the initial current in these muscles was due to $\mathrm{Ca}^{2+}$ influx, and it was suggested (MOUNIER and VASSORT, 1975) that the local transient of positive charge upon $\mathrm{Ca}^{2+}$ influx might shift the activation of $\mathrm{K}^{+}$outflux to the direction of hyperpolarization. Although the initial inward current in frog muscle is due to $\mathrm{Na}^{+}$influx, the properties of the transient outward current observed here seems to be similar and may have the same origin with that of $\mathrm{Ca}^{2+}$-dependent $\mathrm{K}^{+}$current in crab or crayfish muscle.

By the application of the $\mathrm{K}^{+}$channel blockers (TEA or DAP), this transient current was blocked in association with marked potentiation of contractile force which might be caused by prolongation of action potential, as suggested by KHAN and EDMAN (1979). Detubulation of the muscle cell by treating with hypertonic glycerol reduced this outward current, however, with drastic inhibition of tension upon stimulation. These facts indicate that the large part of this current flows through T-tubular membrane and the outward current itself may not be a trigger for initiation of contraction. A similar observation in dantrolene Ringer solution (depression of outward current and contractile force) indicates that the action of dantrolene may be the blocking of tubular current. It has been shown in frog muscle fiber that $\mathrm{T}$-system takes considerable part for $\mathrm{K}^{+}$conductance of membrane (EISENBERG et al., 1971).

We reported previously that extracellularly applied dantrolene inhibited tension development while intracellular dantrolene potentiated transiently the twitch tension, and suggested that these phenomena would reflect the acceleration of release of trigger $\mathrm{Ca}^{2+}$ located on the T-system toward inside the cell by the drug (OBA and HotTA, 1978). It is reasonable to assume that the current through the T-tubular membrane induces the release of trigger $\mathrm{Ca}^{2+}$. After blocking $\mathrm{K}^{+}$ current with DAP, a small fraction of the inward current, which might be present contemporaneously with the outward $\mathrm{K}^{+}$current, began to appear. This inward current had a slower time course than that of the initial one and reached the peak about $30 \mathrm{msec}$ after the peak of the initial inward current. On the other hand, the time required for the initiation of tension generation from the peak of the initial inward current was $25.5 \mathrm{msec}$ (Table 1). The results suggest that the late inward current, which becomes observable by blocking outward current, may be responsible for tension generation. This late inward current is dependent on the initial large inward current and sensitive to TTX. In detubulated fiber and in the fiber incubated in dantrolene Ringer solution, the late inward current was never observed in spite of the depression of the outward current. These facts support the above hypothesis that the late inward current flows through $\mathrm{T}$-system and it may be the first step leading to the release of intracellular $\mathrm{Ca}^{2+}$ stored in SR. In the Ringer solution containing high concentration of dantrolene, the time required for the initiation of tension generation from the peak of initial inward current was significantly lengthened from 25.5 to $31.7 \mathrm{msec}$. This may also indicate that 
signal transmission from T-system to SR was partially blocked by dantrolene. The late inward current, which is a regenerative, $\mathrm{Na}^{+}$-dependent current observed by MANDRINO (1977), has the similar properties with that observed in the present work.

Another kind of the late inward current which is $\mathrm{Ca}^{2+}$-dependent, has been observed in skeletal muscle fiber under the voltage clamp by STANFIELD (1977), TAKEDA (1977) and SAUCHESZ and STEFANI (1978). Increase of $\mathrm{Ca}^{2+}$ influx during the muscle activity has also been confirmed by CurTis (1966). However, the physiological significance of enhanced $\mathrm{Ca}^{2+}$ influx in $\mathrm{E}-\mathrm{C}$ coupling is not clear. Since $\mathrm{Ca}^{2+}$ current observed by these workers had extremely slow time course, it could not be a trigger for initiation of contraction. Obviously, the late inward current observed here was quite different from $\mathrm{Ca}^{2+}$-dependent ones mentioned above.

\section{REFERENCES}

Adrian, R. H., Chandler, W. K., and Hodgkin, A. L. (1970) Voltage clamp experiment in striated muscle fibres. J. Physiol. (Lond.), 208: 607-644.

BASTIAN, J. and NAKAJIMA, S. (1974) Action potential in the transverse tubules and its role in the activation of skeletal muscle. J. Gen. Physiol., 63: 257-278.

Bezanilla, R., Caputo, C., Gonzales-Serratos, H., and Venosa, H. (1972) Sodium dependence of the inward spread of activation in isolated twitch muscle fibers of the frog. J. Physiol. (Lond.), 223: 507-523.

Caille, J., Ildefonse, M., and Rougier, O. (1975) Relation between membrane potential, sodium currents and contraction in frog twitch muscle fibers. J. Physiol. (Lond.), 249: 26 P_ $28 \mathrm{P}$.

Caputo, C. and Dipolo, R. (1973) Tonic diffusion delays in the transverse tubules of frog twitch muscle fibres. J. Physiol. (Lond.), 229: 547-557.

Costantin, L. L. (1970) The role of sodium current in the radial spread of contraction in frog muscle fibers. J. Gen. Physiol., 55: 704-715.

Curtis, B. A. (1966) Ca fluxes in single twitch muscle fibers. J. Gen. Physiol., 50: 255-267.

Eisenberg, R. S., Howell, J. N., and Vangham, P. C. (1971) Ionic conductance of the surface and transverse tubular membrane of frog sartorius fibers. J. Gen. Physiol., 53: 279-298.

Ellis, K. O. and BRYANT, S. H. (1972) Excitation contraction uncoupling in skeletal muscle by dantrolene sodium. Arch. Exp. Pathol. Pharmakol., 274: 107-109.

HeNCEK, M. and ZACHAR, J. (1977) Calcium currents and conductances in the muscle membrane of the crayfish. J. Physiol. (Lond.), 268: 51-71.

HotTA, K., Ова, T., and WATARI, N. (1978) Structure and electrical characteristics of internal membrane system: its role on E-C coupling of skeletal muscle. Abstr. 6th Biophys. Congr., Kyoto, 234.

ILDEFONSE, M. and Rougier, O. (1972) Voltage-clamp analysis of the early current in frog skeletal muscle fiber using double sucrose gap method. J. Physiol. (Lond.), 222: 373-395.

Khan, A. R. and Edman, K. A. P. (1979) Effect of 4-aminopyridine on the excitation-contraction coupling in frog and rat skeletal muscle. Acta Physiol. Scand., 105: 443-452.

KIRSHE, G. E. and NARAHASHI, T. (1978) 3,4-Diaminopyridine, a potent new potassium channel blocker. Biophys. J., 22: 507-512.

MANDrino, M. (1977) Voltage-clamp experiments on frog single skeletal muscle fibers, evidence for tubular sodium current. J. Physiol. (Lond.), 269: 605-625.

MOUNIER, Y. and VASSORT, G. (1975) Evidence for a transient potassium membrane current 
dependent on calcium influx in crab muscle fiber. J. Physiol. (Lond.), 251: 609-625.

OвA, T. and HoттA, K. (1978) Transient effect of intracellular dantrolene on E-C coupling in skeletal muscle. Eur. J. Pharmacol., 51: 81-84.

Sauchez, J. A. and Stefani, E. (1978) Inward Ca current in twitch muscle fibres of the frog. J. Physiol. (Lond.), 283: 267-270.

Stanfield, P. R. (1977) A Ca dependent inward current in frog skeletal muscle fibres. Pflügers Arch., 368: 267-270.

TAKeDA, K. (1977) Prolonged sarcotubular regenerative response in frog sartorius muscle. Jpn. J. Physiol., 27: 379-389. 